\title{
ANÁLISE DA BIOTINA EM AMOSTRAS DE VITAMINAS COMERCIAIS E MANIPULADA UTILIZANDO ESPECTROSCOPIA NO INFRAVERMELHO FTIR-UATR
}

\author{
Isabel Christina Franco Silva ${ }^{1}$ \\ Liu Yao $\mathrm{Cho}^{2}$ \\ Kumiko Koibuchi Sakane ${ }^{3}$
}

Resumo: A biotina, também conhecida como vitamina $H$, é uma vitamina importante aos organismos vivos, necessária no metabolismo das proteínas e dos carboidratos, ela age diretamente na formação da pele. É uma vitamina hidrossolúvel. As principais fontes alimentares de biotina são frutas, nozes, ovos, carnes, leite e levedura. A carência de biotina no homem apesar de rara pode causar dermatite esfoliativa, conjuntivite, descoloração da pele e mucosas, furunculose, seborreia do couro cabeludo e dores musculares. O presente trabalho se propõe a analisar qualitativamente, por espectroscopia no infravermelho, amostras de vitaminas comerciais e manipulada que contenham a biotina. Nas amostras avaliadas foram verificadas que a espectroscopia no infravermelho é viável mesmo para amostras com uma concentração pequena de biotina. Palavras-chave: Biotina; Vitamina H; Espectroscopia no Infravermelho.

\footnotetext{
${ }^{1}$ Engenharia Química/UNIVAP, Brasil. E-mail: isabellsIva@hotmail.com.

2 Engenharia Química/UNIVAP, Brasil. E-mail: liu@univap.br.

${ }^{3}$ Engenharia Química/UNIVAP, Brasil. E-mail: kumiko@univap.br.
} 